\title{
ANÁLISE ESPACIAL DOS CASOS DE LEPTOSPIROSE CANINA A PARTIR DOS SISTEMAS DE INFORMAÇÃO GEOGRÁFICA NO MUNICÍPIO DE BOM JESUS-PI
}

(Spatial analysis of canine leptospirosis cases from Geographical Information Systems in the town of Bom Jesus-

${ }^{1}$ Carlos Eduardo Miranda da Silva, ${ }^{1}$ Darlan Felipe Cardoso de Melo, ${ }^{2}$ Felipe José da Costa Andrade, ${ }^{2}$ Marília Gabryelle Guimarães de Macêdo, 'Larissa Maria Feitosa Gonçalves

1Universidade Federal Rural da Amazônia, Belém, Pará, Brasil. Universidade Federal do Piauí, Bom Jesus, Piauí, Brasil.

*Correspondência: cmsilva1601@gmail.com

RESUMO: A Geografia Médica tem sua trajetória pautada na associação e espacialização de dados referentes a doenças, relacionando aos fatores condicionantes de existência: físicos, sociais e biológicos. Nesse âmbito, é imprescindível o auxílio de uma das ferramentas de alta precisão da Geografia Médica: os Sistemas de Informação Geográfica (SIG). A leptospirose é uma doença zoonótica de distribuição mundial, relatada em humanos, animais domésticos e silvestres. A doença no cão eventualmente o torna reservatório subclínico, uma vez que aparentemente sadio, pode alojar leptospiras e eliminá-las no meio ambiente, promovendo assim, a disseminação para outras espécies e para o homem (VASCOCELLOS, 1993). Nesse contexto, produtos cartográficos com temática pautada para análises epidemiológicas possuem ilustre relevância devido a existência de potencial para demonstrar os focos endêmicos na área de estudo. Portanto, objetivou-se nesse trabalho fazer uma análise espacial englobando a geografia médica e a saúde animal com ênfase nos casos de leptospirose em cães na cidade de Bom Jesus-PI. As 111 amostras sanguíneas de cães usadas nesse estudo foram coletas em novembro de 2018, em postos de vacinação antirrábica, localizados em quatro bairros da cidade de Bom Jesus-PI: Alto Alegre, Cohab, DER e Serra Nova. O diagnóstico foi realizado pela técnica de Soroaglutinação Microscópica (SAM), uma parte na Universidade Federal do Piauí, Campus Universitário Ministro Petrônio Portella em Teresina-PI e outra no Laboratório de Doenças Bacterianas da Reprodução do Instituto Biológico de São Paulo. Utilizou-se dos Sistemas de Informação Geográfica o software Quantum GIS (QGIS), com o intuito de gerar um produto cartográfico cujo objetivo é informar os locais de incidência de Leptospirose canina. Empregaram-se bases de dados cartográficos fornecidos pelo Instituto Brasileiro de Geografia e Estatística (IBGE) e pela Prefeitura do município de Bom Jesus-PI. Por fim, foram inseridos os dados dos testes com resultado "reagente" e relacionados com a localidade a qual cada amostra pertence, a fim de proporcionar a identificação das áreas com maiores ocorrências da doença. Com base na análise das 111 amostras coletadas referentes aos quatro bairros em estudo, constatou-se que 15 destas amostras atestaram reagentes na SAM, equivalendo a um quadro de aproximadamente $13,51 \%$ de cães soropositivos. Constatam-se como locais de maior incidência à leptospirose canina os bairros Cohab e DER, correspondendo respectivamente a $6,3 \%$ e 5,4\% em relação ao total de amostras reagentes. Em contrapartida, os bairros Alto Alegre e Serra Nova apresentaram valor de incidência compatível, igual a 0,9\%. Esta diferença na frequência de cães soropositivos entre os locais mencionados pode ser explicada pela influência dos condicionantes socioeconômicos, da distribuição geográfica e das condições climáticas da região (SILVA et al. 2018). Os resultados deste estudo demonstram a assiduidade de leptospirose canina em duas localidades da cidade de Bom Jesus-Pl, e servem de alerta com relação ao potencial zoonótico e ao desenvolvimento desta patologia para os proprietários e familiares destes animais que residem nas áreas enfatizadas.

Palavras-chave: Análises epidemiológicas; Espacialização de dados; Saúde animal. 


\section{Referências}

SILVA, E. R. D. F. S. et al. Análise sociodemográfica e ambiental para ocorrência de anticorpos antiLeptospira em cães de Teresina, Piauí, Brasil. Ciência \& Saúde Coletiva, v. 23, n. 5, p. 1403-1414, 2018.

VASCONCELLOS, S. A. Leptospirose animal. Anais do Encontro Nacional em Leptospirose, 3. Rio de Janeiro: Ministério da Saúde/FIOCRUZ, p. 62-66, 1993. 